\title{
The Impact of the High Voltage Power Lines Coupling on the Railway Signaling System
}

\author{
Moine El Hajji*, Hassane Mahmoudi and Moussa Labbadi \\ Power Electronics Team, Intelligent Control, automatic and robotic techniques, Department of Electrical Engineering, Mohammadia \\ School of Engineers, Mohammed V University in Rabat, Morocco.
}

Received 3 December 2019; Accepted 17 January 2020

\begin{abstract}
Electromagnetic Compatibility (EMC) disturbance produced by power transmission lines (TL) near the railway installation can generate electromagnetic coupling between the high voltage power line and the signalization cables. In this paper, the voltage induced is analyzed in the signaling system cables located along the high-speed line due to the proximity of an extra high voltage power line. An approximate and Dubanton method have been used in order to have a correct result of the mutual inductance. The proposed technique is compared with the sensitivity threshold of the railway devices in order to check if the presence near high voltage lines will not interfere with the normal operation of the railway equipment. The performance of the Electromagnetic radiation is presented through simulation results.
\end{abstract}

Keywords: EMC, MTL Theory, Electric railway, Power transmission line, Dubanton method.

\section{Introduction}

The location of the Extra High Voltage (EHV) power transmission lines near the railway line may cause induced currents and voltage at the signal cables located along the railway track, the electromagnetic compatibility disturbances depends mainly on the approximation type of interaction mode (coupling) between the high voltage electrical installations and the high-speed train lines, and the type of the geographical layout of the installations. The analysis is mainly carried out on the impact of the electromagnetic coupling between the conductors of the high voltage (HV) power lines and the signal cables that are capable of transmitting the information in real time, such as the ERTMS/ETCS (European Rail Traffic Management System / European Train Control System) transmission cables and which are grouped in computerized interlocking systems [1]. There are different power supply voltages that are provided by different power grid providers and also different type of approximation such as: crossover approximation, oblique approximation, parallel approximation. The main role of the railway signaling system is related to safety and traffic trains [2], and since the signaling is no longer mechanical but transmitted in parallel cables to railway tracks, it has become necessary to study the impact of any intentional disturbing source that may cause the non-functioning of the system. That is why our study is based on the impact of high-voltages power lines coupling on the railway signaling system using the analytical method to calculate the mutual inductance and admittance between the high voltage cables and signal cables through analytical approach in order to have a valid result.

In reference [3], electromagnetic interaction between the transmission lines of high voltage lines and railway catenary

*E-mail address: Moine.elhaiji@gmai.com

ISSN: 1791-2377 @ 2020 School of Science, IHU. All rights reserved.

doi:10.25103/jestr.131.19 is studied when it is positioned in the same pylons. In reference [4], the emc disturbances is estimated when it is caused by high voltage power lines (3-phases) in the steadystate. In reference [5], the electromagnetic interference has been studied to detect the interference between the railway equipment (rolling stock, infrastructure, substation, power lines, track circuit, and axle counter, ...). In reference [6], the system of the autotransformers is modeled and measured through the MTL (Multi-conductor transmission line) model.

In this paper, coupling sections are determined according to the zones of the influence of the disturbing overhead lines with an order of about $10 \mathrm{~m}$ for capacitive coupling and $2000 \mathrm{~m}$ for inductive coupling. An electromagnetic model of railway signal cables and conductors of the overhead power lines will be modelled to closely understand and analyze the electrical behavior of the system under study through the theory of the multi-conductor transmission lines by calculating mutual admittance and mutual inductance through two analytical methods that are approximative and Dubanton method. The approximate method is characterized by a mathematical approach. However, the Dubanton method is characterized in the complex plane and allows to obtain a simpler relation for the calculation of the coefficients of mutual impedance which allows to have a correct calculation up to $10 \mathrm{kHz}$.

\section{Transmission line theory}

\subsection{Application of MTL theory}

EHV power lines present near the railway installation can generate induced currents on the signal cables located along the track. Multi-conductor Transmission Line theory (MTL) will be used in order to represent the coupling between the disturbing and disturbed equipment [7][8]. 
Electromagnetic disturbance in our case in an electrical network are carried by electric field $\mathrm{E}$ and by magnetic field H. There are two types of coupling [9]:

-Capacitive: is the result of the potential difference between two or more conductors.

-Inductive: is the result of a significant coupling between two or more conductors when carrying a large current, which generates a strong magnetic field around the driver.

The model is the electric pylon in parallel to the electric railway track which is represented by the following representation in Fig. 1.

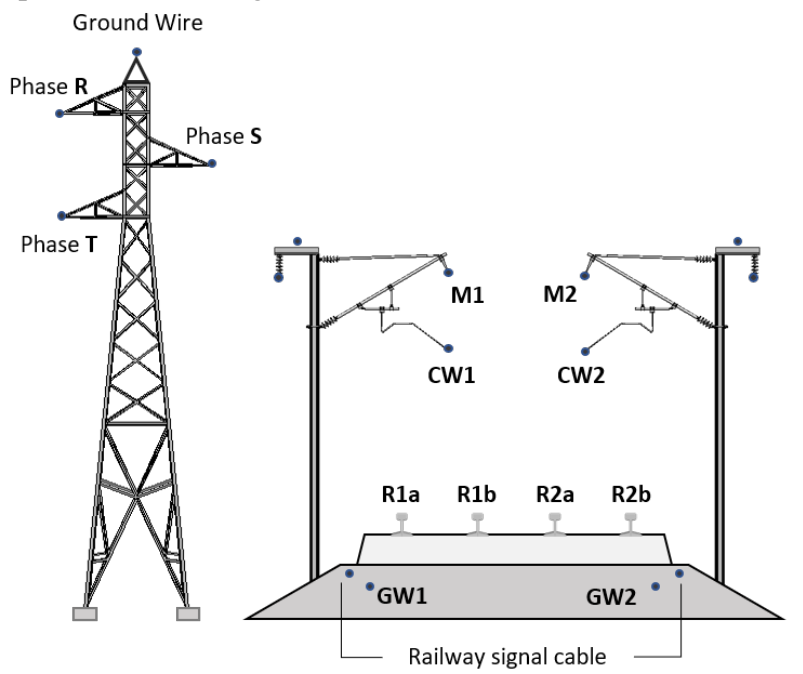

Fig 1. The proximity of the High Voltage pylons and the electric railway. where, $\mathrm{CW}$ : is the contact wire, $\mathrm{M}$ : messenger wire, $\mathrm{GW}$ : ground wire, CdPA: aerial protection cable, CdTE: buried earth cable, R: rail.

The railway signaling on the electric railway line is diversified in order to have a better management of the cantonment and regulation of the speed, formation of the path (control of needle) according to the parameters of the way through a transmission machine track. Everything revolves around the track with the rails, the signaling is grouped into interlocking system stations [10], these cables are parallel to the track as shown in the Fig. 2.

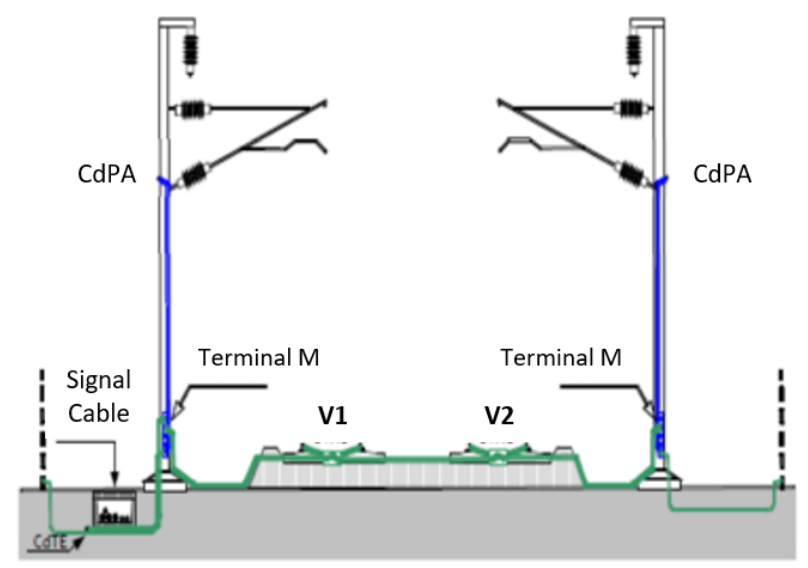

Fig 2. A front view of the railway track.

The equivalent electrical circuit can be illustrated in the Fig. 3 which shows the representation of an electric circuit of four wire transmission line (3-phase power line, railway signal cable) with impedances $\mathrm{Z}_{\mathrm{ii}}$, mutual impedances $\mathrm{Z}_{\mathrm{ij}}$, admittances $Y_{i e}$, and mutual admittances $Y_{i j}$, with $i$ and $j$ are equal to $\{1,2,3,4\}$. The items are distributed with values evaluated per unit length [11][12].

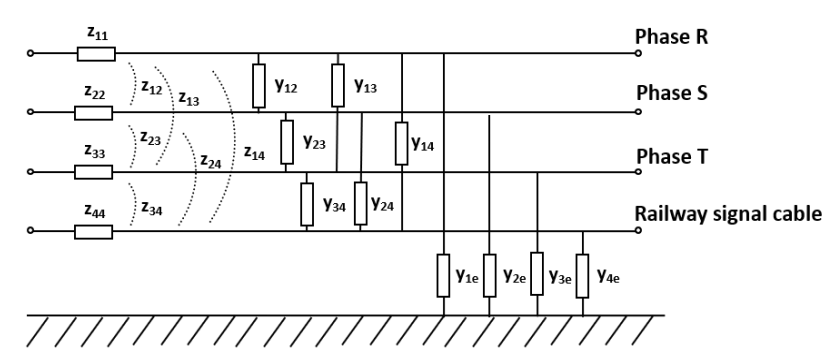

Fig. 3. Four wires transmission lines.

We recognize the overhead lines that correspond to each phase conductor of the high-voltage line and the parallel cables which is the signal conductor and which are the subject of our study.

The transmission line model [13][14] by taking into account the losses in the model is represented in the Fig. 4.

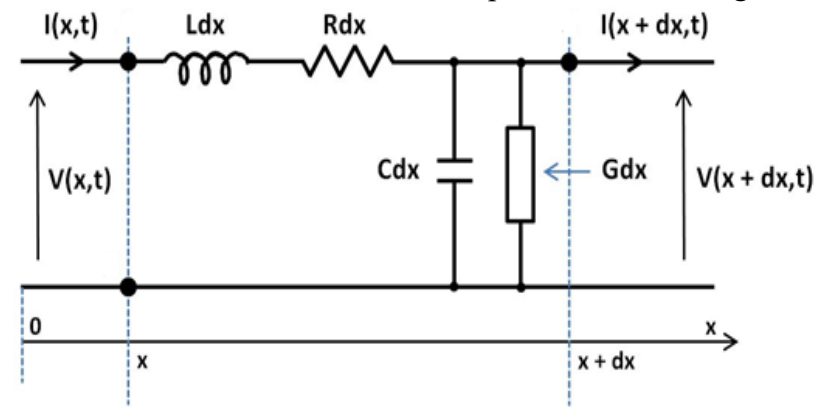

Fig 4. The transmission line model.

The transmission line model is established by writing the differential equations for line voltage and current:

$\left\{\begin{array}{l}\frac{\partial V(x, t)}{\partial x}=-L \frac{\partial I(x, t)}{\partial t}-R I(x, t) \\ \frac{\partial I(x, t)}{\partial x}=-C \frac{\partial V(x, t)}{\partial t}-G V(x, t)\end{array}\right.$

To simplify, the voltage along the phase $\mathrm{R}$ is given by the following relation:

$\frac{\mathrm{dV}_{1}}{\mathrm{dx}}=-\mathrm{Z}_{11} \mathrm{I}_{1}-\mathrm{Z}_{12} \mathrm{I}_{2}-\mathrm{Z}_{13} \mathrm{I}_{3}-\mathrm{Z}_{14} \mathrm{I}_{4}$

with,

$Z_{11}$ is the impedance of the phase $\mathrm{R}$.

$\mathrm{Z}_{11}=\mathrm{R}_{11}+\mathrm{jwL} \mathrm{L}_{11}$

and $Z_{1 j}$ is the mutual impedance between the phase $\mathrm{R}$ and other $j$ lines.

$Z_{1 j}=R_{1 j}+j w L_{1 j}$

Generalizing in a matrix format:

$\frac{\mathrm{d}[\mathrm{V}]}{\mathrm{dx}}=-[\mathrm{Z}][\mathrm{I}]$

with, [Z] is the impedance matrix. 
$[\mathrm{Z}]=\left[\begin{array}{llll}\mathrm{z}_{11} & \mathrm{z}_{12} & \mathrm{z}_{13} & \mathrm{z}_{14} \\ \mathrm{z}_{21} & \mathrm{z}_{22} & \mathrm{z}_{23} & \mathrm{z}_{24} \\ \mathrm{z}_{31} & \mathrm{z}_{32} & \mathrm{z}_{33} & \mathrm{z}_{34} \\ \mathrm{z}_{41} & \mathrm{z}_{42} & \mathrm{z}_{43} & \mathrm{z}_{44}\end{array}\right]$

The coefficients $Z_{i i}$ represent the impedance of the line " $i$ " and to the ground and per unit length and the coefficients $Z_{i j}$ representing the mutual impedance between the line " $i$ " and the line " $j$ " related to the ground [15]. And voltage and current vectors are:

$[\mathrm{V}]=\left[\begin{array}{l}\mathrm{V}_{1} \\ \mathrm{~V}_{2} \\ \mathrm{~V}_{3} \\ \mathrm{~V}_{4}\end{array}\right],[\mathrm{I}]=\left[\begin{array}{l}\mathrm{I}_{1} \\ \mathrm{I}_{2} \\ \mathrm{I}_{3} \\ \mathrm{I}_{4}\end{array}\right]$

As for the current along the line " $i$ " is given by the following relation:

$\frac{d I_{i}}{d x}=-y_{i} V_{i}-\sum_{j=1}^{4} y_{i j}\left(V_{i}-V_{j}\right), i \neq j$

with $y_{i}$ is the admittance of the line " $i$ " and $y_{i j}$ is the mutual admittance between the line " $i$ " and the line " $j$ " related to the ground.

We obtain the following relation in matrix form:

$\frac{\mathrm{d}[\mathrm{I}]}{\mathrm{dx}}=-[\mathrm{Y}][\mathrm{V}]$

with, $[Y]$ is admittance matrix.

$[\mathrm{Y}]=\left[\begin{array}{llll}\mathrm{y}_{11} & \mathrm{y}_{12} & \mathrm{y}_{13} & \mathrm{y}_{14} \\ \mathrm{y}_{21} & \mathrm{y}_{22} & \mathrm{y}_{23} & \mathrm{y}_{24} \\ \mathrm{y}_{31} & \mathrm{y}_{32} & \mathrm{y}_{33} & \mathrm{y}_{34} \\ \mathrm{y}_{41} & \mathrm{y}_{42} & \mathrm{y}_{43} & \mathrm{y}_{44}\end{array}\right]$

The coefficients $y_{i i}$ represent the admittances per unit length and the coefficients $y_{i j}$ represent the admittances between the line " $i$ " and the line " $j$ " related to the ground [16].

There is no direct equivalence between the coefficients of the admittance matrix and the physical admittances as is the case with the coefficients of the impedance matrix. The coefficients of the admittance matrix for one line are linked by the following equations:

$$
\left\{\begin{array}{c}
y_{i i}=y_{i}+\sum_{j=1}^{4} y_{i j}, i \neq j \\
y_{i j}=-y_{i j}
\end{array}\right.
$$

Representing all the conductors of the power lines and the signal line as a multi-conductor transmission is a feasible approach if values of matrix coefficients impedances and admittances are known. The numerical values of these equivalent components are however, difficult to measure under practical conditions, as they depend on the shape, position, permeability and conductivity of the cables, and the permittivity and conductivity of the ground.

2.2 Calculation of the coefficients of the impedance matrix The impedance related of each line and the ground depends mainly on the internal impedance, the external impedance of the conductor and the impedance of the ground represented by the following equation:

zii $=$ zint + zg + jwls with, $z_{\text {int }}$ is the internal impedance, $z_{g}$ is the impedance of the ground of the conductor.

with $l_{s}$ is the inductance per unit length calculated over a perfectly conducting ground.

$1 \mathrm{~s}=\mu 02 \pi \ln 2 \mathrm{ha}$

with $h$ is the height between the conductor line and the ground, and $a$ is the radius of the conductor.

The internal impedance $z_{\text {int }}$ of the conductor is written as follow:

$\mathrm{Z}_{\text {int }}=\frac{1}{2} \mathrm{R}_{\mathrm{d}} \cdot \mathrm{m} \cdot \mathrm{a} \frac{\text { ber m.a+jbei m.a }}{\text { ber'm.a+jbei'm.a }}$

with,

$\mathrm{m}=\sqrt{\mathrm{w} \cdot \mu_{\mathrm{c}} \cdot \sigma_{\mathrm{c}}}$

with $R_{d}$ is the resistance, $\sigma_{c}$ is the conductivity and $\mu_{\mathrm{c}}$ is the permability and ber, bei are Kelvin functions, ber' and bei' are their derivatives.

In order to have an accurate result in an extended frequency band, the impedance of the ground $z_{g}$ is given by Carson formula:

$z_{g}=j w \frac{\mu_{0}}{\pi} \int_{0}^{\infty} \frac{e^{-2 h \lambda} \cdot \cos (\lambda a)}{\lambda+\sqrt{\lambda^{2}-\gamma_{g}^{2}}} \cdot d \lambda$

$\gamma_{g}$ is the ground propagation constant defined by the formula:

$\gamma_{\mathrm{g}}=\sqrt{\mathrm{jw} \mu_{0}\left(\sigma_{\mathrm{g}}+\mathrm{jw} \varepsilon_{0} \varepsilon_{\mathrm{r}}\right)}$

with, $\mu_{0}$ is the permeability of the ground, $\sigma_{g}$ is the conductivity of the ground, $\varepsilon_{0}$ is the permittivity of vaccum, and $\varepsilon_{r}$ is the relative permittivity.

Mathematical equations of Dubanton's simplified method is used in order to calculate parameters of overhead transmission line [17].

Thus, the eigen coefficients $z_{i i}$ of the impedance matrix is calculated through the formula:

$\mathrm{z}_{\mathrm{ii}}=\mathrm{z}_{\mathrm{int}}+\mathrm{jw} \cdot \frac{\mu_{0}}{\pi} \ln \left(\frac{2\left(\mathrm{~h}_{\mathrm{i}}+\mathrm{P}\right)}{\mathrm{a}}\right)$

The mutual coefficients $z_{i j}$ of the impedance matrix is formulated:

$$
\begin{aligned}
& z_{i j}=j w \frac{\mu_{0}}{\pi}\left(\frac{1}{2} \ln \left(\sqrt{\frac{\left(h_{i}+h_{j}\right)^{2}+d^{2}}{\left(h_{i}-h_{j}\right)^{2}+d^{2}}}\right)+\int_{0}^{\infty} \frac{e^{-2 h \lambda} \cdot \cos (\lambda a)}{\lambda+\sqrt{\lambda^{2}-\gamma_{g}^{2}}} \cdot d \lambda\right)(19) \\
& =>z_{i j}=j w \frac{\mu_{0}}{2 \pi} \ln \left(\sqrt{\frac{\left(h_{i}+h_{j}+2 P\right)^{2}+x_{i j}^{2}}{\left(h_{i}-h_{j}\right)^{2}+x_{i j}^{2}}}\right)
\end{aligned}
$$

with, P represents the complex depth

$P=\sqrt{\frac{\rho}{w \mu_{0}}}$

$h_{i}, h_{j}$ are the heights respectively of conductors " $i$ " and " $j$ ", $d$ is the spacing between the conductors " $i$ " and " $j ", \rho$ is soil resistivity, and $w=2 \pi \mathrm{f}$ is the pulsation of the inductor 
current. $x_{i j}$ is the horizontal distance between the two conductors, through the relation below:

$x_{i j}=\sqrt{\mathrm{d}^{2}-\left(\mathrm{h}_{\mathrm{i}}-\mathrm{h}_{\mathrm{j}}\right)^{2}}$

\subsection{Calculation of the coefficients of the admittance} matrix

The admittance matrix for the overhead lines is given by the following relation:

$[\mathrm{Y}]=\mathrm{jw}[\mathrm{P}]^{-1}$

with, $[\mathrm{P}]$ is the potential matrix.

$[P]=\left[\begin{array}{llll}\mathrm{p}_{11} & \mathrm{p}_{12} & \mathrm{p}_{13} & \mathrm{p}_{14} \\ \mathrm{p}_{21} & \mathrm{p}_{22} & \mathrm{p}_{23} & \mathrm{p}_{24} \\ \mathrm{p}_{31} & \mathrm{p}_{32} & \mathrm{p}_{33} & \mathrm{p}_{34} \\ \mathrm{p}_{41} & \mathrm{p}_{42} & \mathrm{p}_{43} & \mathrm{p}_{44}\end{array}\right]$

The eigen coefficients $p_{i i}$ of the potential matrix $[\mathrm{P}]$ are calculated by the following relation:

$\mathrm{p}_{\mathrm{ii}}=\frac{1}{2 \pi \varepsilon_{0}} \cdot\left(\ln \left(\frac{2 \mathrm{~h}}{\mathrm{a}}\right)+\int_{0}^{\infty} 2 \mathrm{k}_{0}^{2} \cdot \frac{\mathrm{e}^{-2 \mathrm{~h} \lambda} \cdot \cos (\lambda \mathrm{a})}{\lambda \cdot \gamma_{\mathrm{g}}^{2}+\mathrm{k}_{0}^{2} \sqrt{\lambda^{2}-\gamma_{\mathrm{g}}^{2}}} \cdot \mathrm{d} \lambda\right)$

The mutual coefficients $p_{i j}$ of the matrix of the potential of two conductors related to the ground are calculated through the relation:

$$
\begin{gathered}
\mathrm{p}_{\mathrm{ij}}=\frac{1}{2 \pi \varepsilon_{0}} \cdot\left(\ln \left(\sqrt{\frac{\left(\mathrm{h}_{\mathrm{i}}+\mathrm{h}_{\mathrm{j}}\right)^{2}+\mathrm{d}^{2}}{\left(\mathrm{~h}_{\mathrm{i}}-\mathrm{h}_{\mathrm{j}}\right)^{2}+\mathrm{d}^{2}}}\right)+\right. \\
\left.\int_{0}^{\infty} 2 \mathrm{k}_{0}^{2} \cdot \frac{\mathrm{e}^{-\left(\mathrm{h}_{\mathrm{i}}+\mathrm{h}_{\mathrm{j}}\right) \lambda} \cdot \cos (\lambda \mathrm{d})}{\lambda \cdot \gamma_{\mathrm{g}}^{2}+\mathrm{k}_{0}^{2} \sqrt{\lambda^{2}-\gamma_{\mathrm{g}}^{2}}} \cdot \mathrm{d} \lambda\right)
\end{gathered}
$$

with,

$$
\mathrm{k}_{0}^{2}=\mu_{0} \varepsilon_{0} \mathrm{w}^{2}
$$

\section{Electromagnetic disturbance caused by overhead lines}

Analytical calculations from simplified mathematical equation according to the Dubanton method previously described associated to the theory of the transmission lines will be applied in order to have a nodal approach.

We will deal the phenomenon of electromagnetic disturbance coupling by disrupting different types of coupling mainly:

- Magnetic induction.

- Electrostatic coupling.

\subsection{Magnetic induction phenomena}

The schematization of the magnetic coupling phenomenon between the signaling cable and HV line is shown in the Fig. 5.

The expression of the electromotive force induced $\mathrm{E}$ along the line is written in the form of the sum of the electromotive forces induced in each elementary section $e_{i j}$. The value of the magnetic induction will be calculated through the dubanton and approximate formula.
$E=i, j e i j$

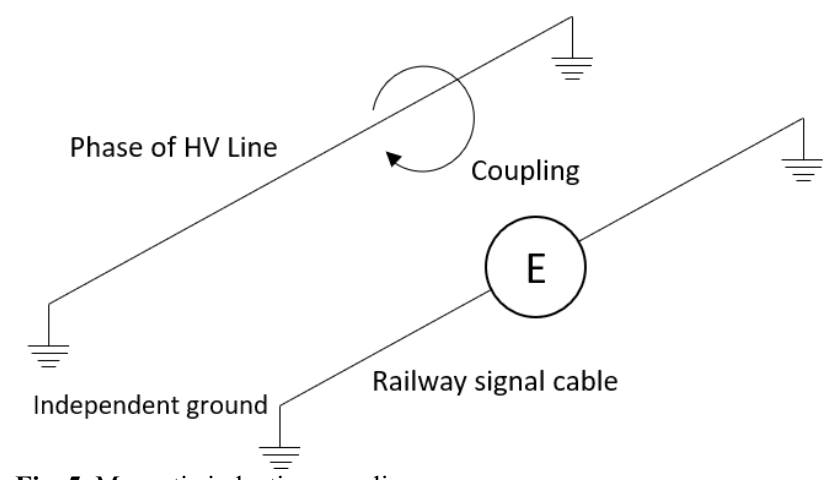

Fig. 5. Magnetic induction coupling.

According to the Dubanton formula already expressed in the previous chapter:

$$
z i j=j w \mu 02 \pi \ln (h i+h j+2 P) 2+x i j 2(h i-h j) 2+x i j 2
$$

However, for the approximate formula is represented in the following formula:

$\mathrm{z}_{\mathrm{ij}}=\mathrm{jwM}$

with, $\mathrm{M}$ depends mainly on the value of $x$, in $\mu \mathrm{H} / \mathrm{km}$ and it is equal to:

$$
\begin{aligned}
& -\quad \text { For } x \leq 10: \\
\mathrm{M} & =142+46 \mathrm{x}-198 \ln (\mathrm{x})-1.4 \mathrm{x}^{2} \\
& -\quad \text { For } x>10:
\end{aligned}
$$$$
M=400 x^{-2}
$$

with,

$$
x=d \sqrt{\frac{w \mu_{0}}{\rho}}
$$

The magnetic field varies with the current flowing in the cable. It also depends on the geometry of the conductors and the current flowing in the nearby conductors.

For our case cables in triangles, the magnetic field is determined by the following relation:

$\mathrm{B}=\frac{\sqrt{6} \mathrm{~d}_{\mathrm{pp}} \mathrm{I}}{10 \mathrm{r}^{2}}$

with, $d_{p p}$ is the distance between phases, $I$ is the current flowing in the high voltage line, $r$ is the distance of the field relative to the source.

\subsection{Electrostatic coupling phenomena}

When two conductors are above ground then they are coupled together by capacities. That is why the variable voltage conductor creates a variable electric field. It causes induced voltages and currents on overhead conductors placed near the catenary $2 \times 25 \mathrm{kV}$ system [18][19].

Capacitive coupling as seen in the Fig 6 . between HV lines and signal cables is considered to be negligible in our study since they are in chutes and buried under the ground [20]. 


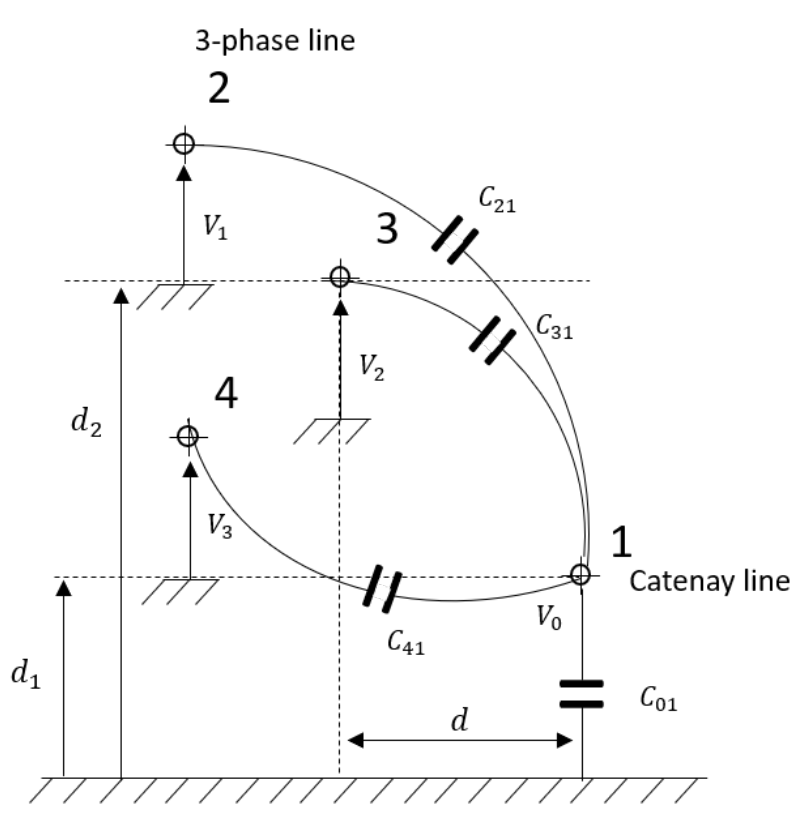

Fig. 6. capacitive coupling between 3-phase lines and catenary.

Only the catenary system that is susceptible to be charged with electricity.

$$
\mathrm{V}_{0}=\frac{\mathrm{Q}_{0}}{\mathrm{C}_{01}}=\frac{\mathrm{C}_{21} \mathrm{~V}_{1}+\mathrm{C}_{31} \mathrm{~V}_{2}+\mathrm{C}_{41} \mathrm{~V}_{3}}{\mathrm{C}_{21}+\mathrm{C}_{31}+\mathrm{C}_{41}}
$$

The induced current $I_{0}$ flowing in the conductor is proportional to the induced voltage $V_{0}$ and the length of parallelism 1 .

$\mathrm{I}_{0}=\mathrm{V}_{0} \cdot \mathrm{C}_{04} \cdot \mathrm{w} \cdot \mathrm{l}$

\subsection{Results and comparison with the standard limits}

The electric and magnetic field are modeled by COMSOL Multiphysics as shown in the Fig. 7. The values of the parameters in the worst case are listed in the Tab. 1 in order to calculate the mutual inductance according to the two methods, magnetic field and electric field.

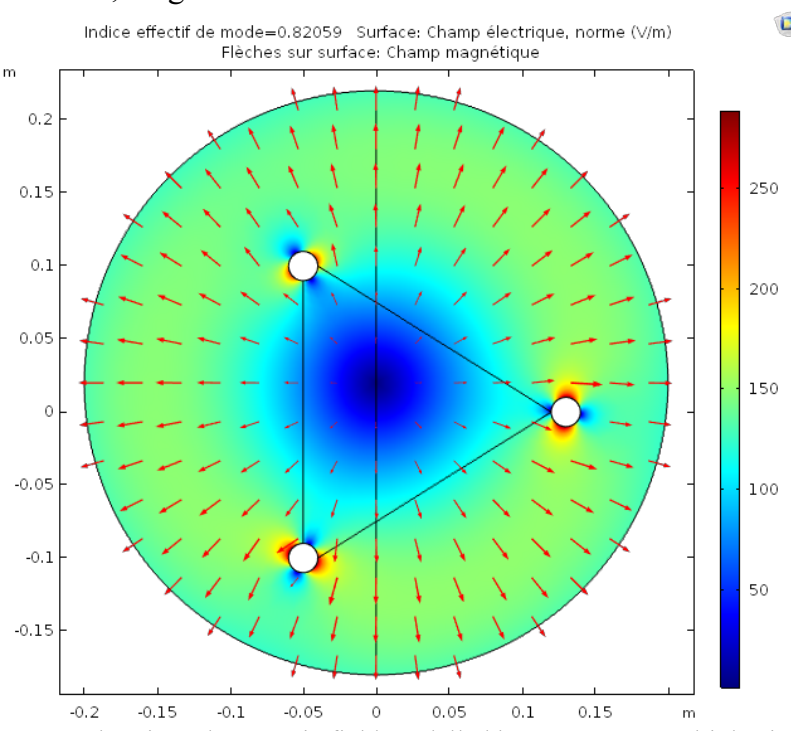

Fig. 7. Electric and magnetic field modelled by COMSOL Multiphysics.

Table 1. fixed values

\begin{tabular}{c|c|c}
\hline Variable & Value & Unit \\
\hline$U_{n}$ & 440 & $\mathrm{kV}$ \\
$\rho$ & 280 & $\Omega . \mathrm{m}$
\end{tabular}

\begin{tabular}{c|c|c}
$\mathrm{f}$ & 50 & $\mathrm{~Hz}$ \\
$h_{i}$ & 10 & $\mathrm{~m}$ \\
$h_{j}$ & 10 & $\mathrm{~m}$ \\
$l$ & 1.5 & $\mathrm{~km}$ \\
$d$ & 15 & $\mathrm{~m}$ \\
$d_{1}$ & 5 & $\mathrm{~m}$ \\
$d_{2}$ & 20 & $\mathrm{~m}$ \\
\hline
\end{tabular}

We obtain the following results after calculation the mutual inductance, the results of the two methods are presented in Tab. 2.

Table 2. Compared Values of the mutual inductance

\begin{tabular}{c|c|c}
\hline Formula & Value & Unit \\
\hline Dubanton & 2.346 & $\mu \mathrm{H} \cdot m^{-1}$ \\
Approximate & 2.507 & $\mu \mathrm{H} \cdot m^{-1}$ \\
\hline
\end{tabular}

The capacitive coupling between the HV lines and the signaling cables for our study will be negligible because the cables are shielded and in the internal induced voltages are mitigated by the transfer of impedance of these cables and the result of the values settled in the worst case is inferior below the required limits. For induced voltage and current flowing the catenary:

$V_{0}=6,8 \mathrm{~V}, I_{0}=0,1109 \mathrm{~mA}$

For the magnetic field: $B=3,8 \cdot 10^{-5}$

The limits are given below for signaling equipment located within $3 \mathrm{~m}$ of the track according to standard EN 61000-4-8 EN 50121-4 [21-26]:

- $\quad$ For AC system:

$\mathrm{B}=\mu_{0} \mathrm{H}=3,8 \cdot 10^{-4} \mathrm{~T}$

- For DC system:

$\mathrm{B}=\mu_{0} \mathrm{H}=1,25 \cdot 10^{-4} \mathrm{~T}$

It can be seen that the results obtained are within the limit range of the standardization. Electromagnetic interference due to the presence of EHV pylons near the railway line can be supported by signaling equipment.

To determine the mutual inductance of this model, we can also use the abacus method which will be detailed in another article in order to know the most optimal method and which links bandwidth and central frequency to the physical dimensions capable of providing the functional results of complex problems based on a graphical reflection tool. Thanks to the curve depending on the value as a function of the distance between the high-voltage lines and the rail signaling circuit.

\section{Conclusion}

The purpose of this analysis is to determine the electromagnetic field radiated by the high voltage power lines and their impact on the signaling equipment. This field is calculated and compared with the immunity threshold of the equipment according to the standardization test of the EN 61000-4-8 and the EN 50121.To sum up, the voltages induced in the conductors of the signaling cables due to the proximity of the EHV lines are lower than the limit value for the worst case. The proximity of the power lines does not constitute a 
major risk of electrostatic and magnetic interference induced on the signal cables. However, the electromagnetic field tests are essential to be able to be proven during EMC measurements on railway yard by taking into account the risks related mainly to the risks of electrostatic interference that can generate electrostatic discharges and capacitive current, and to the risks of magnetic interference compared to signaling equipment by field-to-envelope coupling.

\section{Acknowledgments}

This paper was supported by the research laboratory of the electrical department within the Mohammadia Engineering School, Mohammed V University in Rabat Morocco.

This is an Open Access article distributed under the terms of the Creative Commons Attribution License

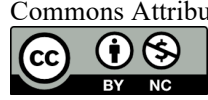

\section{References}

[1] L. Junting, D. Jianwu, M. Yongzhi (2016). "NGCTCS: Nextgeneration Chinese train control system", Journal of Engineering Science and Technology Review, Vol. 9, Issue 6, 122-130. https://doi.org/10.25103/jestr.096.18

[2] Z. Yanpeng, D. Jianwu, L. Xiaojuan, Y. Fan,’Optimized Handover Algorithm Based on Stackelberg Games in CBTC Systems for Urban Rail Transit", Journal of Engineering Science and Technology Review, Vol. 7, Issue 3, 2014, 127-132, doi: 10.25103/jestr.073.21

[3] A. Novitskiy, I. Konotop, D. Westermann, "EMC Problems caused by combinations of EHV Transmission lines and electrified railway lines”, International Conference on Renewable Energies and Power Quality, Cordoba, Spain, 2014, doi:10.24084/repqj12.437.

[4] Y. Li, F. P. Dawalibi, and S. E. Services, "a Parametric Analysis of Ac Interference Caused By High."

[5] J. D. Sanz-Bios, J. Garzon-Nunez, R. Loiero, J. Felez, "Electrical Disturbances from High Speed Railway Environment to Existing Services", Electrical Generation and Distribution Systems and Power Quality Disturbances, 2011, doi: 10.5772/22133.

[6] R. Cella, G. Giangaspero, A. Mariscotti, A. Montepagano, P. Pozzobon, M. Ruscelli, M. Vanti, "Measurement of AT Electric Railway System Currents at Power-Supply Frequency and Validation of a Multiconductor Transmission-Line Model", IEEE transaction on power delivery, 2006, doi: 10.1109/TPWRD.2006.874109.

[7] S. Minucci, M. Pagano, and D. Proto, "Model of the $2 \times 25 \mathrm{kV}$ high speed railway supply system taking into account the soil-air interface," Int. J. Electr. Power Energy Syst., vol. 95, pp. 644-652, 2018.

[8] Z. Mazloom, "Multi-conductor transmission line model for electrified railways: a method for including responses of lumped devices", Vol. 3, pp.29-44, Stockholm, Sweden, 2010.

[9] A. Morant, Å. Wisten, D. Galar, U. Kumar, and S. Niska, "Railway EMI impact on train operation and environment," IEEE Int. Symp. Electromagn. Compat., 2012.

[10]N. Theethayi et al., "A theoretical study on the consequence of a direct lightning strike to electrified railway system in Sweden," Electr. Power Syst. Res., vol. 74, no. 2, pp. 267-280, 2005.

[11]N. Theethayi, R. Thottappillil, Y. Liu, and R. Montano, "Important parameters that influence crosstalk in multiconductor transmission lines," Electr. Power Syst. Res., vol. 77, no. 8, pp. 896-909, 2007.

[12]S. Rönnberg and M. Bollen, "Power quality issues in the electric power system of the future," Electr. J., vol. 29, no. 10, pp. 49-61, 2016.

[13]K. Jia, "Electromagnetic Noise generated in the electrified railway propulsion system", PhD Thesis, Stockholm, Sweden, 2011.
[14]F. Diagnosis, W. Packet, and E. N. Network, "J estr," vol. 6, no. 2, pp. 150-154, 2013.

[15] Adesegun A. Ogunsola, "Railway interference management: TLM modelling in railway applications", Loughborough University, Vol. 4, pp.66-100, June 2008.

[16]A. Dolara, M. Gualdoni, S. Leva, "EMC disturbances on Track Circuits in the $2 \times 25 \mathrm{kV}$ high speed AC railway systems", IEEE Trondheim PowerTech, 2011, doi: 10.1109/ptc.2011.6019206.

[17]A. Déri, G. Tevan, "Mathematical Verification of Dubanton's Simplified Calculation of Overhead Transmission Line Parameters and its Physical Interpretation", Archiv ftir Elektrotechnik, 191$198,1981$.

[18] S. Minucci, M. Pagano, D. Proto, "Model of the $2 \times 25$ kV high speed railway supply system taking into account the soil-air interface", International Journal of Electrical Power \& Energy Systems, Vol. 95, pp 644-652, 2018, doi:10.1016/j.ijepes.2017.09.017.

[19] M. El Hajji, H. Mahmoudi, M. El Azzaoui, "Harmonic Analysis Caused by static converters of the railway high speed train and their impact on the track circuit", International Conference on Wireless Technologies, Embedded and Intelligent Systems, Fez, Morocco, 2019, doi: 10.1109/WITS.2019.8723777.

[20]L. Xiaotian, Z. Haijing, Q. Bo, H. Bochong, "EMC in rail transport", Energy Procedia, Vol. 104, pp. 526-531, 2016, doi: https://doi.org/10.1016/j.egypro.2016.12.089.

[21] CENELEC EN 61000-4-6, "Electromagnetic Compatibility - part 6: Testing and measurements techniques -5 : surge immunity to conducted disturbancesn induced by radio frequency fields", August 2007.

[22] CENELEC EN 61000-4-8, "Electromagnetic Compatibility - part 4: Testing and measurements techniques - section 8: Power frequency magnetic field immunity test", September 1993.

[23] CENELEC EN 61000-4-10, "Electromagnetic Compatibility - part 4: Testing and measurements techniques - section 10: damped oscillatory magnetic field immunity test", September 1993.

[24] CENELEC EN 61000-4-13, "Electromagnetic Compatibility - part 4: Testing and measurements techniques - section 13: Harmonics and inter-harmonics including mains signaling at ac power port, low frequency immunity tests", June 2002.

[25]CENELEC EN 50121-4, "Railway Application: Electromagnetic Compatibility, Emission and Immunity of signaling and telecommunication appliances", July 2006.

[26]CENELEC EN 50121-1, "Railway Application: Electromagnetic Compatibility, Part 5: Emission and immunity of railway fixed power supply installations", july 2006. 